\title{
Effect of Unsafe Actions and Conditions with Work Accidents in the Rotary Section of Plywood Industry Pt.x Jember, Indonesia
}

\author{
Fihris Maulidiah Suhma ${ }^{1}$, Ancah Caesarina Novi Marchianti. ${ }^{2}$, Isa Ma'rufi ${ }^{3}$ \\ ${ }^{1}$ Graduate Student, Magister Program of Public Health Education, ${ }^{2}$ Medical Doctor, Philosophyof Doctor, \\ Faculty of Medicine, ${ }^{3}$ Public Health Lecturer, Faculty of Public Health Education, \\ Jember University, East Java (Indonesia)
}

\begin{abstract}
The current industrial development is getting more advanced and developing every year. However, these developments have not been matched by awareness in understanding and carrying out work in accordance with good occupational health and safety regulations so that work accidents still occur in every industrial environment, including the plywood industry. The general objective of this study is to analyze the circumstances that affect the incidence of corporate work accidents in Jember, Indonesia. This research is a quantitative study, using an analytic observational research design with a cross sectional method. The population used was all the rotary plywood industry workers of PT. X Jember Regency as many as 339 workers, with a sample size of 76 people. The sampling technique used in this study was quota random sampling. The results showed that there was an influence between unsafe actions on the incidence of work accidents with the Sig. .042, and there is an influence between unsafe conditions and work accidents with the Sig. .016. The occurrence of work accidents does not just happen but happens because of something wrong either because of the fault of the worker or because of the unsafe conditions of the worker or the work environment.
\end{abstract}

Keywords: Industry, Work Accident, Unsafe Action, Worker

\section{Introduction}

Potential occupational health and safety hazards (K3) lead to long-term impact risks (physical, chemical, biological, and ergonomic factors hazards), direct safety risks (fire, electrical short circuit, mechanical hazards, housekeeping), risks to disruption of daily activities (drinking water facilities, toilets, dining room or canteen, first aid facilities, transportation), and psychological risks (sexual harassment, work stress, violence in the workplace) (10). Work accidents occur in the process of interaction due to contact between humans and tools, materials, and the work environment. $88 \%$ of work accidents occurred due to unsafe actions, $10 \%$ due to unsafe conditions, and $2 \%$ due to things that could not be avoided. Work accidents can occur due to a work environment that is not conducive (unsafe conditions), and can also occur due to factors of the workers themselves (unsafe actions) ${ }^{(7)}$.

Unsafe action is a dangerous action committed by workers which occurs due to various reasons such as lack of knowledge, inability to work, physical disabilities, unsafe attitudes and behavior, stress, lack of skills, decreased concentration, lack of motivation, job satisfaction. Meanwhile, unsafe conditions are unsafe conditions of equipment, machines, aircraft, materials, work environment, work processes, and work systems (6).

Based on data obtained from BPJS TK in Isafety Magazine December 2018 period, the number of work accidents in 2015-2016 has decreased, namely, as many as 110,285 cases in 2015 , as many as 101,367 cases in 2016. Work accident cases increased again in 2017, namely as many as 123,000 cases, and increasing in 
2018, namely as many as 157,313 cases, ranging from minor, serious accidents to those with fatal impacts such as disability or death.

The plywood industry is one type of industry that uses a lot of machines in its production process. According to the Ministry of Forestry of the Republic of Indonesia in CDMI, the number of plywood factories still operating in 2013 was around 150 companies. One of the largest plywood producing provinces is East Java, amounting to $705,519 \mathrm{~m}^{3}$. The number of wood industries in Jember Regency since 2013-2017 is as many as 139 industries which are generally engaged in the manufacture of furniture such as cots, cupboards, and the manufacture of other home materials. There are four plywood industries in Jember Regency including, PT. Murocco, PT. Kayu Lapis Sejahtera, PT. WijayaCahaya Timber, and PT.X, and of these companies PT.X is the industry with the highest rate of work accidents, namely 402 cases of work accidents from December 2015 to August $2018^{(3)}$.

Based on the data obtained from the research site, there are 10-17 work accidents every month, which are based on several factors. First, unsafe action factors such as ignoring the use of PPE, not being careful when installing rotary engine blades, not complying with the SOP for using tools properly, joking with colleagues, rushing to finish the job. Second, unsafe conditions such as cables that are scattered and some are peeled off, working equipment that is not tidy, wood chips scattered on the floor, unsuitable work clothes, namely wearing a short sleeve shirt that makes the sleeve get caught in the wood peeling machine rotating, and there are other factors that cause work accidents that are not identified.

There are five areas in the PT.X plywood industry, namely, log pool (where to wash logs), rotary (cutting wood into veneer or wood sheets), press dryer (drying), and core repair (veneer repair), quality control ( sorting and packing veneers that are ready to send, and of the five areas the rotary area is the area most frequently accidents at work. In the rotary area there is a wood cutting machine, where the machine continues to operate and rotate. Change of blades on each existing machine, still using the manual method, namely workers changing knives every half and every shift of work or when it is felt that the knife is no longer sharp.Cutting and stripping logs in this area produces wood chips, as well as the remaining unused sheets of wood. often occurs in rotary parts, namely, the arm is scratched because the clothes are stuck into the rotating wood cutting machine, the hand cut by a hand clipper machine knife, the hand or finger is scratched by a rotary knife when installing the knife on the machine, the leg is hit by a log, punctured by a nail, and the eye is hit by a wood chip The work accidents mentioned above occurred due to unsafe actions and unsafe conditions ${ }^{(11)}$.

The general objective of this study was to determine the effect of unsafe actions and unsafe conditions with work accidents that occurred in the rotary section of PT.X, Jember Regency.

\section{Methods}

This research was categorized into a quantitative research which exerted analytic descriptive research design. This research collected the research data through quota random sampling. The research population was taken from all workers of plywood industry of PT. X Jember District in rotary section as many as 339 workers. The total sample of this research were 76 respondents. The method of analysis was multivariate and descriptive analysis. The dependent variable in this research was case of work accident, while independent variables were unsafe action and unsafe condition. The multivariate analysis was used and aimed to identify the effect of unsafe action and unsafe condition variables to the occurrence of work accident. Further, the data analysis in this research employed simple linear regression analysis method. This method was used because the data scale for either dependent variable or independent variables was categorical.

\section{Research Findings}

The unsafe action was a dangerous action which could harm people or environment. The unsafe action could occur based on internal factor from either work environment or external factor from outside of work environment. The following table 1 would list the unsafe actions which performed by workers at PT. $\mathrm{X}$ in the rotary section, Jember District. 
Table 1. The Overview of Unsafe Action at PT. X Jember District

\begin{tabular}{|c|c|c|c|}
\hline No. & Indicator & $\mathbf{n}$ & \% \\
\hline 1. & Workers act safely & 1 & 1,3 \\
\hline 3. & Workers act unsafely & 75 & 98,7 \\
\hline \multicolumn{2}{|c|}{ Total } & 76 & 100 \\
\hline
\end{tabular}

Based on the table 1, it referred that the majority of workers in about 75 respondents $(98,7 \% 0$ still worked with unsafe actions, and only 1 respondents $(1,3 \%)$ who have worked in safe action.

A work environment must be in safe and comfortable condition for the workers, wither it was related to work character, work machine and tool, and work environment condition should fulfill several points that must be implemented in order to create a safe work environment persistently, as the use of proper and complete personal protective equipment, work environment was free from hazardous material, lighting, ventilation, and many other supportive aspects. The condition of work environment in rotary section at PT. X Jember could be seen on this following table 2:

Table 2. An Overview of Unsafe Condition at PT. X Jember District

\begin{tabular}{|c|c|c|c|}
\hline No. & Indicator & n & $\%$ \\
\hline 1. & Safe condition & 75 & 98,7 \\
\hline 3. & Unsafe condition & 1 & 1,3 \\
\hline \multicolumn{2}{|r|}{ Total } & 76 & 100 \\
\hline
\end{tabular}

Based on the table 2, it referred that the majority of workers in about $75 \%$ respondents $(98,7 \%)$ were in unsafe condition, while only 1 respondent $(1,3 \%)$ who was working in safe condition.

The accident in workplace was not a case expected by either the workers or industry itself. But, the work accident was an unplanned and unexpected occurrence that just happened. Moreover, the work accident could be happened from either human factor or work environment factor. The following table 3 was an identification of work accident case at PT. X Jember District, especially in rotary section:

Table 3. The Identification of Work Accident Case

\begin{tabular}{|c|c|c|c|c|c|c|c|c|c|}
\hline \multirow{2}{*}{ No. } & \multirow{2}{*}{$\begin{array}{c}\text { Variable of Work } \\
\text { Accident }\end{array}$} & \multicolumn{6}{|c|}{ Severity Level of Work Accident Case } & \multirow{2}{*}{$\mathbf{n}$} & \multirow{2}{*}{$\%$} \\
\hline & & Light & $\%$ & Medium & $\%$ & Severe & $\%$ & & \\
\hline 1. & Rotary Knife & 0 & 0 & 48 & 63,1 & 28 & 36,9 & 76 & 100 \\
\hline 2. & Hand Clipper Knife & 0 & 0 & 49 & 64,5 & 27 & 35,5 & 76 & 100 \\
\hline 3. & Material (log wood) & 0 & 0 & 23 & 30,3 & 53 & 69,7 & 76 & 100 \\
\hline 4. & Roll and Conveyor & 0 & 0 & 46 & 60,5 & 30 & 39,5 & 76 & 100 \\
\hline
\end{tabular}


Based on the table 3 regarding to an identification of work accident case, based on the injury severity level, the work accident case which caused by rotary knife, there were 48 respondents $(63,1 \%)$ who have gotten an accident with medium injury level, and 28 respondents $(36,9 \%)$ who have gotten an accident with severe injury level. In term of hand clipper knife, there were 49 respondents $(64,5 \%)$ who have gotten an accident with medium injury level, and 27 respondents $(35,3 \%)$ who have gotten an accident with light injury level. In term of material (log wood), there were 23 respondents $(30,3 \%)$ who have gotten an accident with medium injury level and 53 respondents $(69,7 \%)$ who have gotten an accident with light injury level. Last, in term of roll and conveyor, there were 46 respondents $(60,5 \%)$ who have gotten an accident with medium injury level and 30 respondents $(39,5 \%)$ who have gotten an accident with light injury level.

The most influential factor between unsafe action and occurrence of work accident on the workers of PT. $\mathrm{X}$ Jember District would be analyzed in this following table 5.

Table 5. The Most Influential Factors between Work Stress, Unsafe Action, and Work Accident Case

\begin{tabular}{|c|c|c|c|c|c|}
\hline Variable & B & S.E & $\operatorname{Exp(B)}$ & $\mathbf{T}$ & Sig. \\
\hline Unsafe action & .887 & .386 & .253 & 2.299 & .024 \\
\hline Unsafe condition & -1.428 & .558 & -.288 & -2.557 & .013 \\
\hline Constant & 49.209 & 5.947 & & 8.275 & .000 \\
\hline
\end{tabular}

The dimension of effect was indicated by EXP (B) value or odd ratio (OR) value. Based on the analysis result on the table 5, it referred the odd ratio (OR) value on variable of unsafe action, the odd ratio (OR) value was 0.253 which was denoted that the workers who worked with unsafe action would get the probability of work accident 0.245 times higher than the workers who worked with safe action. Next, on the variable of unsafe condition, the odd ratio (OR) value was -0.288 which was referred that the workers who were in unsafe condition would tend to have probability of work accident -0.288 times higher than the workers who were in safe working condition. Regarding to that analysis result, it showed that the most influential variable between unsafe action, unsafe condition, and work accident occurrence was unsafe action variable.

\section{Discussion}

Working, struggling to fulfill and achieve life goals, stress can be a great motivator. However, things that must be considered and emphasized are how to manage stress so that it does not get worse, heavier, and prolonged because it can reduce the body's condition caused by physical and psychological disorders caused as a result of stress that is not immediately controlled. Someone who is diligent and accustomed to working under pressure may make stress a flavor and see threats as a challenge. Maybe they are able to turn stress into a possibility or opportunity to grow and develop in their work. For someone who is not used to stress in his work, he will show anxiety, helplessness, and even isolation because he feels threatened in facing a change or problem ${ }^{(11)}$. Some of the factors that contribute to work stress are insufficient time to complete work, unclear purpose of work, unclear instructions from leaders, no recognition of employee work results, lack of opportunities to participate in the workplace, responsibilities answer without clear authority, lack of social interaction between workers and leaders resulting in social disparities and differences in vision and mission, dangerous and unpleasant working conditions, less comfortable workplaces, less control than supervisors or leaders ${ }^{(2)}$. Unsafe action is an action that is endangering someone so that it causes an accident or incident. The 
more someone acts unsafe, the more likely it is that an accident will occur. Minimizing the occurrence of work accidents must also be minimized so that workers act unsafe, namely by conducting safety training for new workers and holding additional training for other workers. Efforts to add training to change the mindset and habits of workers who still often underestimate work safety and act carelessly at work $^{(3)}$.

The things that underlie someone tend to take unsafe actions because they feel they are experts in their field, are in a hurry to finish a job, are accustomed to doing unsafe actions and have never had work accidents (workplace culture), following other workers who are not obedient to safety, lack of supervision from the leadership so that workers underestimate safety measures, there is no motivation from the leadership to work in safety, there is no clear warning or sanction related to unsafe actions ${ }^{(3)}$. The majority of workers, namely $80.9 \%$, act unsafe at work and this is due to inadequate knowledge of how to act safely at work and low motivation to work to take safe actions while working. Unsafe actions that many workers do, such as not wearing Personal Protective Equipment (PPE) by $62.7 \%$, joking while working $(23.7 \%)$, and placing oneself in an inappropriate position at work $(13.5 \%)^{(}$

1). There are several causes of work accidents, starting from the basic cause, namely the underlying causes in general, the occurrence of work accidents covering the social and economic environment, including stress. This basic cause can affect how the actions taken by workers while working and also the conditions that occur in the work environment which, if not controlled, will result in work accidents. All the components that cause work accidents affect each other, but there are those that affect directly and there are those that have an indirect effect.

The effect of unsafe actions and unsafe conditions on work accidents that occur in construction which concludes that the unsafe action variable has a 1,170 times higher effect on the incidence of work accidents than unsafe conditions which have an effect on 1,116 times higher on the incidence of work accidents ${ }^{(6)}$. The first position that causes work accidents is unsafe action and after that unsafe conditions are followed by other factors ${ }^{(8)}$. The practice of working safely for rotary employees shows the same results, namely as many as $85 \%$ of work accidents that occur are caused by the behavior of workers who work unsafe such as not wearing protective clothing while working, not wearing hand gloves, not wearing protective shoes with correct, do not tie the wedge of the rotary machine properly and carefully, removing the safety installation (machine guarding leveling) while others are working ${ }^{(9)}$.

Suggestions that can be given by researchers are based on the results of the research, namely that the supervisors are expected to provide input about 3-5 minutes for each shift change related to the SOP of machines and work equipment, especially for machines that must operate continuously, and provide understanding to employees about the importance of health and work safety to minimize work accidents. In addition, the company is expected to train a safe work culture for all employees. It is necessary to carry out a sudden inspection (sidak) by the relevant Manpower Office to ensure that the work health and safety culture and programs in the company are running well.

\section{Conclusion}

Work accidents occur unconsciously, uncontrollably, unplanned, unexpectedly and unwanted by anyone. Unexpected because behind the accident there is no element of intent, let alone planned. There is an influence between unsafe actions and the incidence of work accidents with the Sig. .042, and there is an influence between unsafe conditions and work accidents with the Sig. .016.

\section{Conflict of Interest: None}

\section{Source of Funding: Self}

Ethical Clearance: This research has undergone ethical test in ethics commission of health research of Faculty of Dentistry, University of Jember in this following registration number 926/UN25.8/KEPK/ DL/2020

\section{References}

1. Djatmiko, RiswanDwi.Occupational Health and Safety. Yogyakarta: Deepublish.; 2016. p.30.

2. DahlanMaarifah. Analysis of the Causes of Work 
Accidents Based on the Results of the Work Accident Investigation of PT.PAL Indonesia. JurnalKecehatanMasyarakat. Jurnal LPPM Unasman 2017;1(3):2442- 8884.https://journal. lppm-unasman.ac.id.

3. Hartoyo Edi., QomariyatusSholihah, RahmiFauzia, DwiNurRachmah.Breakfast \& Productivity. Malang: UB Press ; 2015. p.15.

4. HasibuanMalayu.Human Resource Management. Jakarta: PT. Bumi Aksara; 2012. p.5

5. IdrisFahmi.Dynamics of Industrial Relations. Yogyakarta: Deepublish.; 2018. p.5-6.

6. Primadianto, Sandra, danRatna. The Effect of Unsafe Act and Unsafe Condition on Construction Work Accidents. JurnalDimensiPratamaTeknikSipil. 2018:7 (1).http://publication.petra.ac.id/index.php/ teknik-sipil/article/view/7036/6386
7. RamliS.OHSAS 18001 Occupational Health and Safety Management System.Jakarta: Dian Rakyat.; 2010. p. 17

8. RivaiVeithzal.Human Resource Management For Companies.Jakarta: PT. raja Grafindo Persada.; 2004. p.10.

9. Suma'mur.Company Hygiene and Occupational Health (Hiperkes).Jakarta: CV Agung Seto; 2013. p. 8

10. Sucipto. Occupational Health and Safety. Yogyakarta: Gosyen Publishing.; 2014. p.12-13

11. Transiska, Dewi.,Nuryanti, Taufiqurrahman. The influence of work environment and human factors on the Accident Rate of Employees at PT. PutriMidaiBangkinang, Kampar Regency. JurnalPromosiKesehatan Indonesia. 2019;10(2):5565. https://jom.unri.ac.id/index.php/JOMFEKON/ article/view/7928/7600 